\title{
Parameters Design and Control Strategy of Cascade STATCOM Based on LCL Filter
}

\author{
Zhenglong Xia, Liping Shi and Xiaodong Yang \\ School of Information and Electrical Engineering China University of Mining and \\ Technology \\ Quan-Shan District, Xuzhou, Jiangsu Province, 221116, PR China \\ zhenglong.xia@shangruo.com,shiliping98@126.com,24661883@qq.com
}

\begin{abstract}
Frequency controlling technique applied to the coal mine electromechanica equipments results in the absence of reactive power and harmonics pollution, which brings hidden troubles to power net in coal mine. Considering electrontechanical equiprnent's safe and economic operation, this study opened with the mathemotical model and parameters design of cascade STATCOM based on LCL filter. Then a low-pass filter time delay link and a PI controller were adopted for ensuring high dynamic response-and low-frequency stable accuracy of the inner current loop. Eventually the repetitive control loop based on internal principal was used as outer current loop to realize zero static error tracking of referenced harmonic current, so that both high dynamic response and small steady-state error were obtained. Simulation and the actual devick experiment validate the feasibility of the design.
\end{abstract}

Keywords: LCL filter, Cascade STATCOM, Control Strategy, Reactive Compensation, Parameters design

\section{Introduction}

The improvement of electric power quality is always a hot topic [1-3]. Power quality problems of mine eleetricity supply are made worse with frequent start-brake and great capability of coal mine electromechanical equipments, as well as the widespread adoption of frequency changers, rectifiers and soft starters. Lower power factor, larger harmonic current, unbalance of three phase voltages, voltage fluctuation and flicker cause much hidden trouble to the security of mine safety production. STATCOM becomes a trend with fast dynamic response, extensive range of regulation, smaller volume, and high quality waveform of compensating current. At present, the multiple-transformer structure of STATCOM has so many drawbacks, such as high cost, large occupying space, high active power loss and nonlinear characteristics of transformer [4-6]. Cascade STATCOM is widely used for less area occupation, modular design, individual phase control and its saving investment and maintenance costs of transformers [7].

L filter is widely employed in cascade STATCOM because of simple structure, low cost and easy to control [8-9], but because of the low high-frequency attenuation rate, the filtering effects of high-frequency ripple are limited. The characters of low-frequency gain and highfrequency attenuation determine that LCL filter is the most ideal filtering method. Parameters design and stable control of LCL filter are the hotspot and frontier in the research of power electronics $[10-13,17]$. The control strategy of current loop is divided into two categories: direct-current control and indirect-current control. The indirect-current control is rarely used 
in practical for bad dynamic performance. The direct-current control mainly includes traditional PI control, repetitive control, and proportional resonant control. Traditional PI control can track DC signal with zero steady-state error, but has a worse tracking precision of harmonic referenced current. Repetitive control can realize high-accuracy control of the whole frequency band but has the drawback of one grid frequency period delay [14]. Proportional resonant control has disadvantages of complex control structure. The control strategy in article [15-16] can not restrain parallel resonance between the grid-side inductor and the filter capacitor of LCL filters.

Considering the feasibility and superiority of LCL filter, this study achieves reactive power compensation and harmonic suppression by the coordination of LCL filter and cascade STATCOM. At first, this study puts forward the mathematical model and parameters design scheme of cascade STATCOM based on LCL filter. Then the closed-loop stability control of ${ }^{\bullet}$ inner current loop is resolved by the time delay link and traditional PI controller for ensuring better dynamic performance and low-frequency stable precision. Finally, for the bad performance in tracking harmonic signals of the inner current control loop the repetitive control loop based on internal principle is used as outer current loop to realize zero static error tracking of referenced harmonic signal. The results show that the current control strategy proposed in this paper can efficiently restrain the harmonic interference and track the reference current. Simulation results and the device experiments verify the effectiveness of the proposed current control strategy.

\section{Model and Parameters Design of LCLPilter in Cascade STATCOM}

The topology structure of cascade STATCOM based on LCL filter is shown in Figure 1. $\mathrm{L}_{1}$ represents the inverter-side inductor $\mathrm{L}_{\text {represents }}$ the grid-side inductor. C represents the filter capacitor. $\mathrm{R}_{\mathrm{d}}$ represents the resistance of capacitor. $\mathrm{u}$ represents the output phase voltage. $i_{1}$ represents the output phase current. $u_{s}$ represents the phase voltage of the grid. $i_{2}$ represents the grid-side earrent of LCL filter. $u_{c}$ represents the capacitor voltage. $i_{c}$ represents the capacitor current. $i_{s}$ represents the grid current. $i_{L}$ represents the load current.

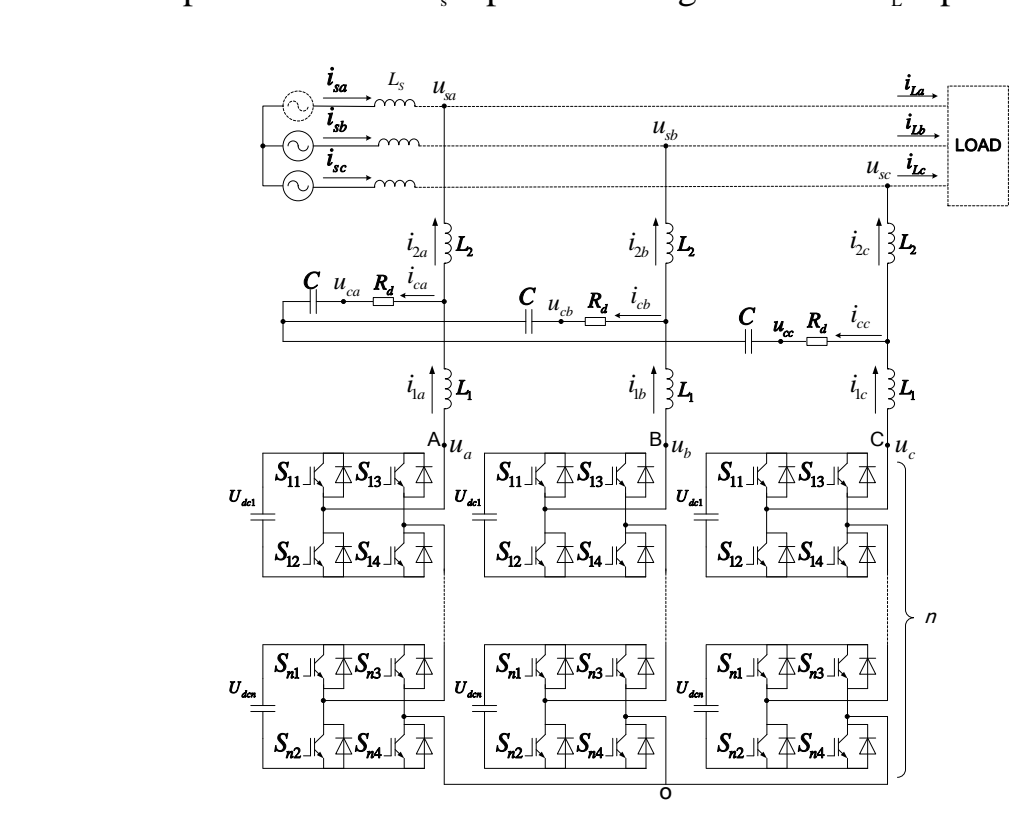

Figure 1. Structure diagram of cascade STATCOM based on LCL filter 


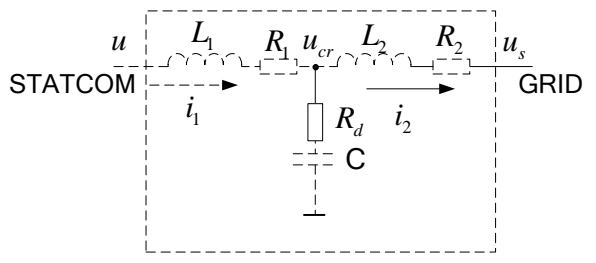

Figure 2. Schematic diagram of LCL filter

Ignoring $\mathrm{R}_{1}$ and $\mathrm{R}_{2}$, the current control block diagram and the transfer function from gridside current $\left(i_{2}\right)$ to inverter-side output voltage $(u)$ are easy to obtain from Figure 2.

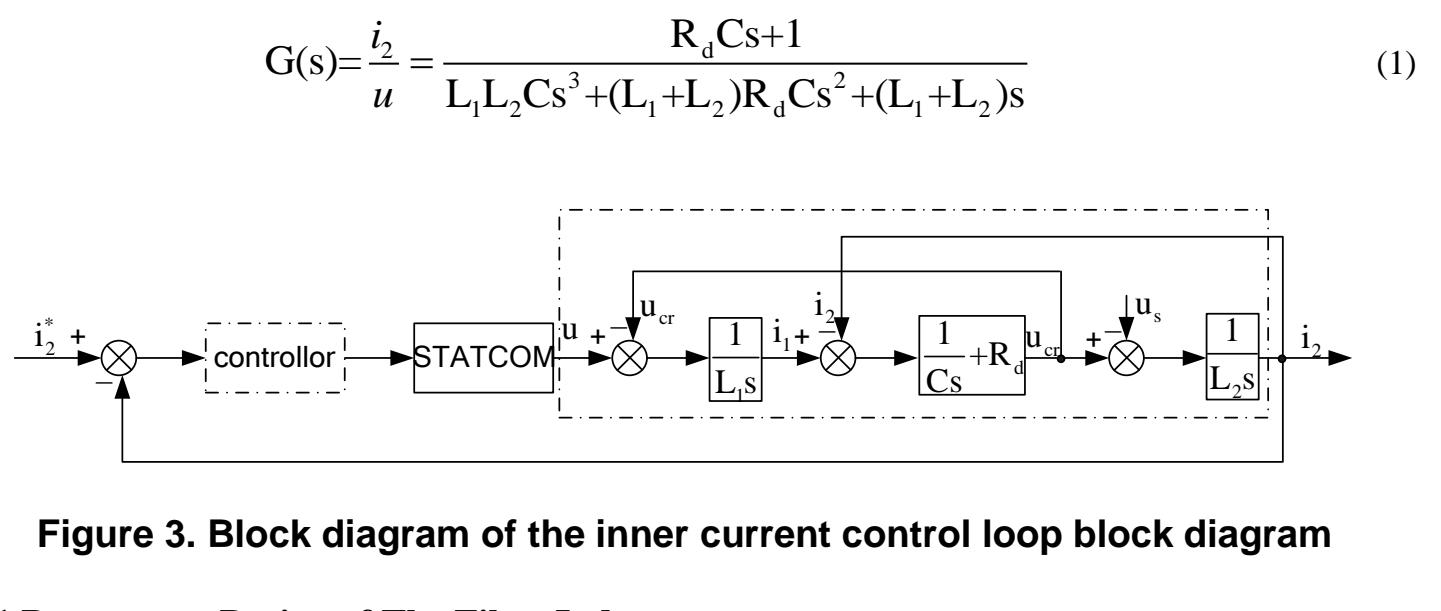

\subsection{Parameters Design of The Filter Inductors}

Parameters design of the indyctors in $\mathrm{KCL}$ - filter is based on the principle as follows (Device Capacity $S_{N}=2.8 \mathrm{M} v \mathrm{gr}$, The $\mathrm{carrier}$ frequency $f_{c}=10.8 \mathrm{kHz}$, the sample frequency $f_{s}=21.6 \mathrm{kHz} \cdot 1$ (CLine voltage $U_{\mathrm{s}}=6 \mathrm{KV}$ ):

1. According to [18], the voltage drop at the inductors of LCL filter must be less than $10 \%$ of the phase voltage of the grid

$$
\omega\left(L_{1}+L_{2}\right) I_{N}<10 \% \times U_{N} / \sqrt{3} \Rightarrow\left(L_{1}+L_{2}\right)<4.1 \mathrm{mH}
$$

2. In order to limit the short circuit current and the harmonic current, the inductance of inductors should not be too small. The minimum value of inductance is determined by the ripple current which is chosen between 10\%-20\%.

Each phase of cascade STATCOM can be equivalent to the single-phase bridge inverter. The equivalent DC voltage expressed as $u_{d c \Sigma}$ is $5600 \mathrm{~V}$. The equivalent switching frequency is $5.4 \mathrm{KHz}$. The proportion of switch-on time of the i-th period of carrier wave is expressed as $d_{i}$. The modulation ratio is expressed as $m_{a}$. The period of carrier wave is expressed as $T_{s}$. The average value of $\mathrm{H}$-Bridge fundamental voltage is expressed as $u_{a v}$. Assuming that the 
fundamental currents flowing through the filter inductors are zero, the ripple current is showed in Figure 4.

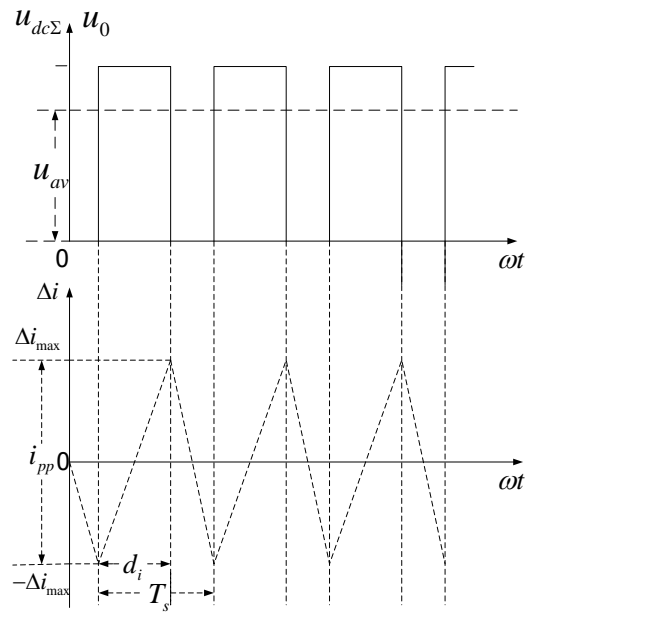

Figure 4. The waveform of output voltage and current of the single-phase bridge inverter.

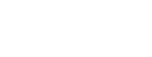

When the average value of H-Bridge fundamental voltage is equal to $u_{s}$, the fundamental current flowing through the filter inductors is zero, and only then the current flowing through the filter inductors is the ripple current, the formula is deduced as follows:

$$
\begin{aligned}
& \frac{u_{a v}}{u_{s}(\omega t)} \frac{d_{i}(\omega t) u_{a} \Sigma}{m_{a} u_{d \sigma \Sigma} \sin \omega t}=1 \Rightarrow d_{i}(\omega t)=m_{a} \sin \omega t \\
& \rightarrow V i_{p p}=\frac{u_{d c \Sigma}-u_{a v}}{\ell L} d_{i} T_{s}=\frac{u_{d c \Sigma} T_{s}\left(1-m_{a} \sin \omega t\right)}{L} m_{a} \sin \omega t \\
& \mathrm{~V}_{\text {Nax }}=\frac{i_{p p}}{2}=\frac{u_{d c \Sigma} T_{s}}{8 L} \leq 20 \% I_{N} \Rightarrow L \geq \frac{u_{d c \Sigma}}{20 \% \times 8 \times I_{N} f_{s}}=1.2 \mathrm{mH}
\end{aligned}
$$

In conclusion, the value range of inductance of the inductors in LCL filter is

$$
1.2 \mathrm{mH}<L_{1}+L_{2}<4.1 \mathrm{mH}
$$

Considering of the cost, the value of inductance is chosen as $1.2 \mathrm{mH}$. The proper ratio of $L_{1}$ to $L_{2}$ is between 4 and 6 which is obtained in article [18], so the inductance values are

$$
L_{1}=0.96 m H \quad L_{2}=0.24 m H
$$




\subsection{Parameters Design of Filter Capacitors}

In order to guarantee the efficiency of cascade STATCOM, reactive power absorbed by filter Capacitors must be less than $5 \%$ of rated capacity.

$$
Q=3 \times \omega C \times\left(\frac{U_{N}}{\sqrt{3}}\right)^{2} \leq 5 \% S_{N} \Rightarrow C \leq \frac{5 \% S_{N}}{3 \times \omega \times\left(\frac{U_{N}}{\sqrt{3}}\right)^{2}} \Rightarrow C \leq 12.4 \mathrm{uF}
$$

The value of capacitance in this paper is chosen as $8 \mathrm{uF}$.

For making the harmonics current flow through the filter Capacitors as more as possible and the resonant frequency of LCL filter should avoid appearing in low or high frequency band, parameters design should meet the following requirements.

$$
\begin{gathered}
X_{C}=\left(\begin{array}{ll}
0.1: & 0.2
\end{array}\right) X_{L 2} \\
10 f_{1}<f_{\text {res }}<f_{c} / 2 \Rightarrow 0.5 \mathrm{kHz}<f_{\text {res }}<5.4 \mathrm{kH} / \mathrm{z}
\end{gathered}
$$

\section{Control Strategy of Cascade STATCOM Based on LCL Filter}

The spectrum graph of LCL filten and Lfilter with the same inductance in Figure 5 shows that both filters hare the same frequency characteristics below the resonant frequency, but above the resonant frequency, the attenuation rate of LCL filter is far higher than L filter. To the switching frequency of $10.8 \mathrm{kHz}$, the attenuation rate of LCL filter is $-53.8 \mathrm{~dB}$, while the attenuation rate of L filter is $-38.2 \mathrm{~dB}$. So the filtering effect of LCL filter is better than L filter.

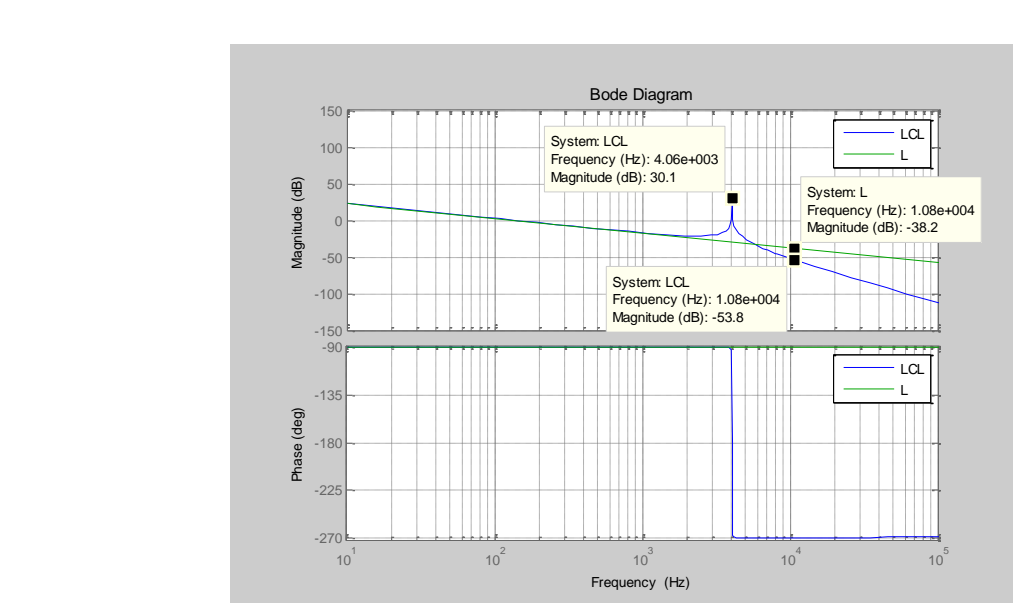

Figure 5. Bode plots of LCL filter and L filter with the same inductance 
According to Figure 5, the phase-frequency curve crosses -180 degree at the resonance frequency of $4.06 \mathrm{kHz}$, and the peak value of amplitude-frequency curve reaches $30.1 \mathrm{~dB}$, so the closed-loop control of LCL filter is not stable. But over the range of frequencies from $140 \mathrm{~Hz}$ to $3.9 \mathrm{kHz}$, the amplitude of $\mathrm{G}(\mathrm{s})$ is below $0 \mathrm{~dB}$. Another significant point to be considered is that the low-frequency amplitude of $\mathrm{G}(\mathrm{s})$ is not so high that the stability precision is not high. So the regulation steps must balance the needs of increase of the lowfrequency amplitude and the positive gain margin at -180 degree crossing frequency.

Traditional PI control can increase the low-frequency gain for improving low-frequency stable precision. Considering the improvement of the stability, the ideal accumulation function of PI controller is weakened as the quasi-accumulation function.

The damping of PI controller: $\mathrm{r}=0.005$.

The gain of PI controller: $\mathrm{K}=4$

The corner frequency of PI controller: $f=1 / T=1884 \mathrm{rad} / \mathrm{s}$

So the transfer function of traditional PI controller is obtained

$$
\mathrm{C}_{\mathrm{PI}}(\mathrm{s})=\mathrm{K} \frac{\mathrm{Ts}+1}{\mathrm{Ts}+\mathrm{r}}=\frac{4 \mathrm{~s}+4 \times 1884}{\mathrm{~s}+0.005 \times 1884}
$$

In order to keep the stability, -180 degree crossing frequency should be adjusted to the range of frequencies from $140 \mathrm{~Hz}$ to $3.9 \mathrm{kHz}$ by a second-order low-pass filter with the corner frequency $\omega_{n}=2 \pi \times 2000 \mathrm{rad} / \mathrm{s}$, the dareping ratio $\leqslant \neq 0.707$. So the transfer function is

$$
\mathrm{F}_{2}(\mathrm{~s})=\frac{\omega_{\mathrm{n}}^{2}}{\mathrm{~s}+2 \xi \omega_{n} s+\omega_{\mathrm{n}}^{2}}=\frac{(2 \pi \times 2000)^{2}}{\mathrm{~s}^{2}+2 \times 0.707 \times 2 \pi \times 2000 s+(2 \pi \times 2000)^{2}}
$$

8

The open-loop transfer function of inner current loop is

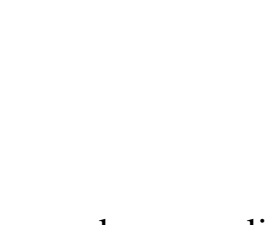

$$
\mathrm{G}_{\mathrm{o}}(\mathrm{s})=\mathrm{C}_{\mathrm{PI}}(\mathrm{s}) \mathrm{F}_{2}(\mathrm{~s}) \mathrm{G}(\mathrm{s})
$$

The open-loop amplitude-frequency curve after regulation in Figure 6 shows that the PI controller and the second-order low-pass filter not only increase the low-frequency amplitude but also increase the phase shift of G(s) at the corner frequency which reduces from $4.06 \mathrm{kHz}$ to $2.79 \mathrm{kHz}$ with the gain margin of $11.2 \mathrm{~dB}$. 


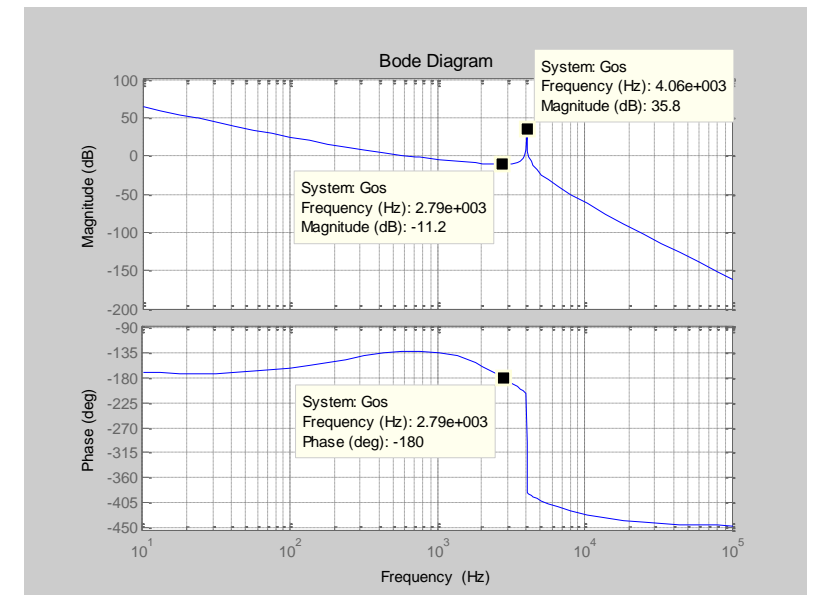

Figure 6. Bode plots of $G_{o}(s)$ after the time delay regulation

Bode diagram of closed-loop transfer function $\mathrm{G}_{\mathrm{c}}(\mathrm{s})$ in Figare 7 shows that the output can track the command signal accurately below $100 \mathrm{~Hz}$. The output amplitude is fundamentally the same as the input amplitude and the phase lag problemappears above $100 \mathrm{~Hz}$. Due to the high high-frequency attenuation of LCL filter, the harmonic component of the grid-side current is so low that the gain of PI controller can be designed, higher for guaranteeing better low-frequency control precision. At the closed-loop resonance frequency, the resonance peak amplitude is $7.01 \mathrm{~dB}$. Above all, the feedback control of griasside current in the inner current loop can acquire better fundamental-wavecurrent control effect but has bad performance in tracking harmonic command signal. It is hard to realize zero static error for tracking harmonic current. The phase lag for tracking $400-\mathrm{Hz}$ signail reaches 36.3 degree, which seriously influencing the precision of the harmonic compensation of cascade STATCOM.

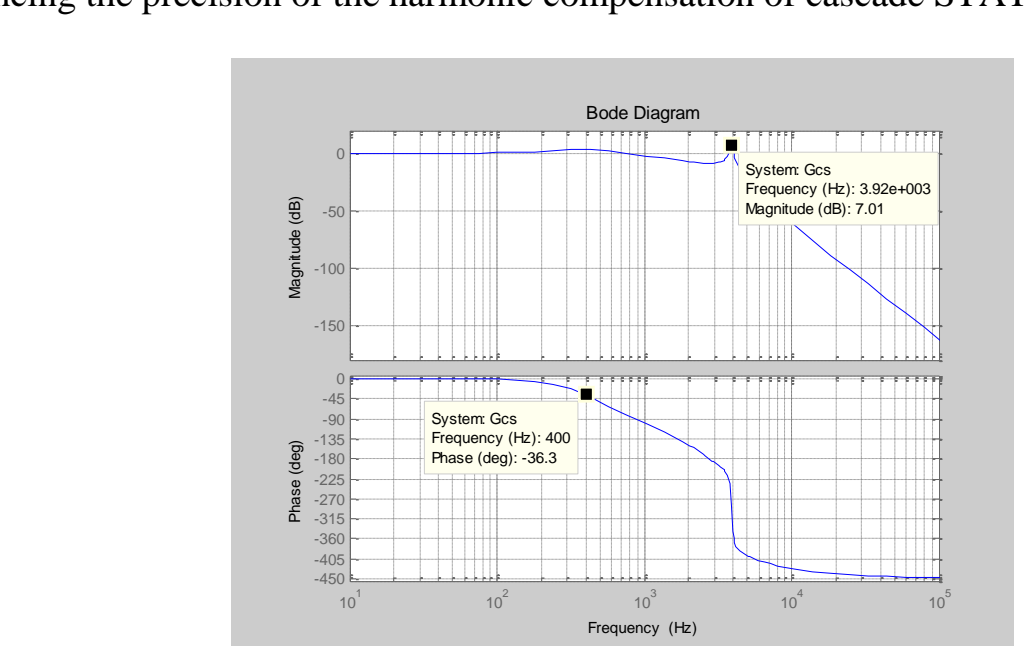

Figure 7. Bode plots of $\mathrm{G}_{\mathrm{c}}(\mathrm{s})$

The feedback control of grid-side current in the inner current loop can acquire better fundamental-wave current control effect but has bad performance in tracking harmonic command signal. For the high-gain of harmonic signal of repetitive internal model controller, the repetitive control is adopted as the outer control loop. Because the regulation of the repetitive control in the outer current control loop aims at reducing tracking error of the inner 
current control loop, the regulation time is greatly reduced. The system achieves better tracking performance and higher steady precision by combining the inner and outer current loop. The system structure is shown in Figure 8 . The repetitive controller includes three parts: the repetitive internal model controller, the cycle delay part $z^{-N}$ and the regulation part $\mathrm{S}(\mathrm{z})$. Considering the stability, the ideal integral is weakened as quasi-integral, so Q (z) is slightly less than 1 and is chosen as 0.98 in this paper.

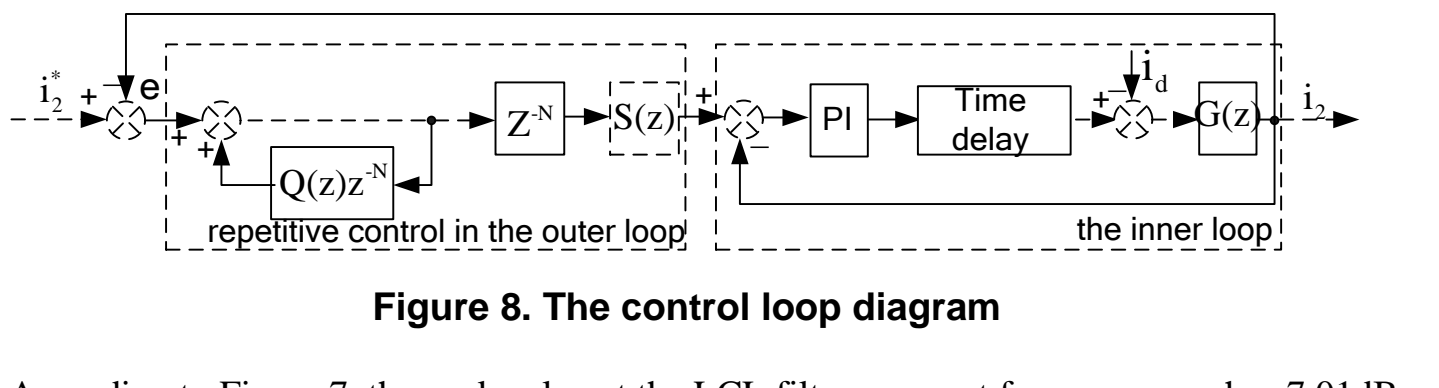

According to Figure 7, the peak value at the LCL filter resonant frequency reaches 7.01dB. For avoiding losing low-frequency gain, notch filter is adopted to attenuate the resonance peak. Considering the amplitude frequency and the phase frequency characteristics of notch filter, the trap frequency is chosen as $5.4 \mathrm{kHz}$ for notonly restraining the resonance peak but also having an ideal phase frequency curve The transfe function of notch filter is $F(z)=0.25\left(z^{2}+1\right)^{2} / z^{2}$. Five-beat delay of the digital control $z^{5}$ is used to compensate the phase delay of inner current control. The repetitive control compensator is

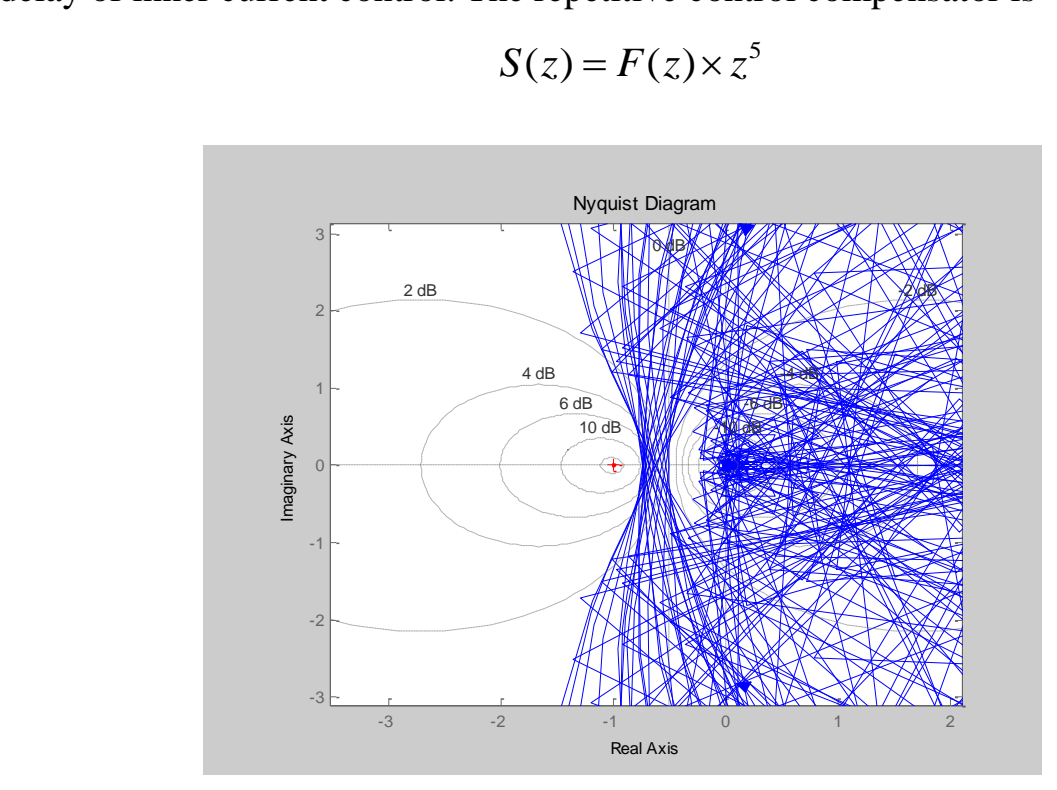

Figure 9. Nyquist diagrams of $\mathrm{T}_{\mathrm{o}}(\mathrm{z})$

The nyquist curve of the open-loop transfer function of dual-loop control given by $\mathrm{T}_{\mathrm{o}}(\mathrm{z})=\frac{1}{1-\mathrm{Q}(\mathrm{z}) \mathrm{z}^{-\mathrm{N}}} \mathrm{z}^{-\mathrm{N}} \mathrm{S}(\mathrm{z}) \mathrm{Gc}(\mathrm{z})$ does not enclose the critical point $(-1,0 \mathrm{j})$ in Figure 9, so the closed-loop system is stable. 
The tracking error of inner loop is

$$
\left(i_{2}^{*}-i_{2}\right) Q_{c}(z)=i_{2} \Rightarrow \Phi_{e}=\frac{i_{2}^{*}-i_{2}}{i_{2}^{*}}=\frac{1}{1+G_{c}(z)}
$$

The tracking error of dual-loop is

$$
\left(i_{2}^{*}-i_{2}\right) \times \frac{z^{-N}}{1-Q(z) z^{-N}} S(z) \times G_{c}(z)=i_{2} \Rightarrow \Phi_{e}=\frac{i_{2}^{*}-i_{2}}{i_{2}^{*}}=\frac{z^{N}-Q(z)}{z^{N}-Q(z)+S(z) G_{c}(z)}(1,5)^{\bullet}
$$

The bode graph of $\Phi_{e}$ in Figure 10 shows that the tracking errof of dual-oop at $400-\mathrm{Hz}$ signal reduces from $-7.94 \mathrm{~dB}$ (equivalent to $40 \%$ ) of the imner loop to $-37.4 \mathrm{~dB}$ (equivalent to $1.35 \%$ ), and the phase frequency curve of dual-loop can be considered to be the same with the command signal, which play an important role in harmonic compensation of cascade STATCOM.

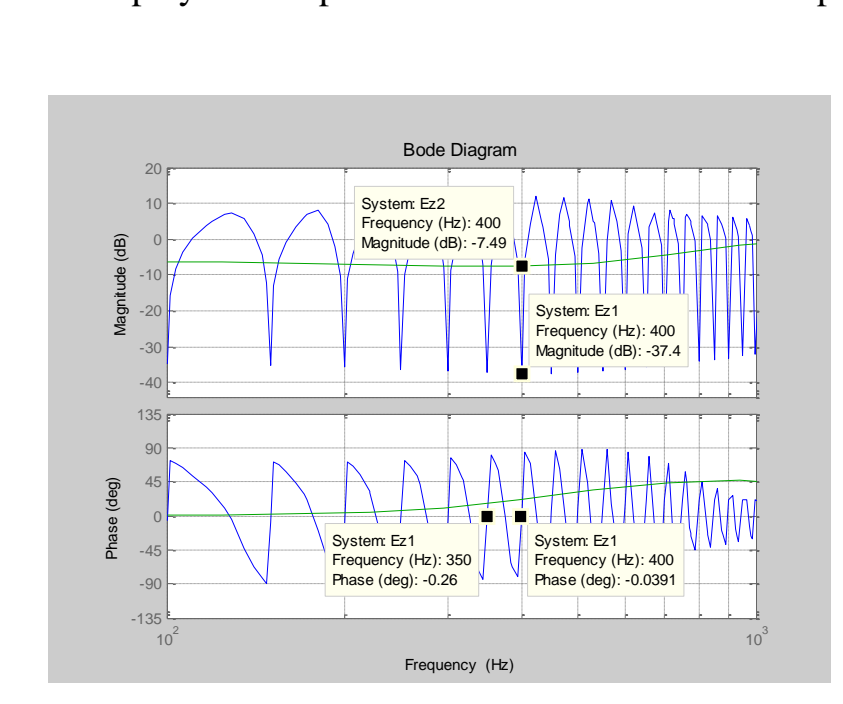

Figure 10. The bode graph of $\Phi_{e}$

Bode graph of dual-loop control for grid disturbance restraint in Figure 11 shows that the ability of the inner loop for grid disturbance restraint becomes gradually worse with the increase of the frequency. Eight-order harmonic amplitude attenuation of the inner loop is only $-10.5 \mathrm{~dB}$. After adding the repetitive control in the outer loop, the ability of the dual-loop for grid disturbance restraint is greatly enhanced. Eight-order harmonic amplitude attenuation of the dual-loop is $-48 \mathrm{~dB}$. The dual-loop control ensures good restrain capability of grid disturbance below $800 \mathrm{~Hz}$. 


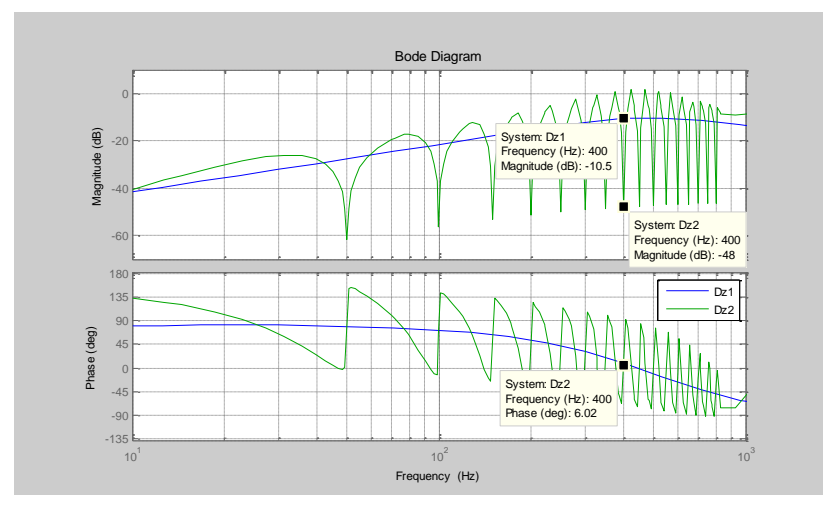

Figure 11. the bode graph of $e(z) / i_{d}(z)$

Above all, the dual-loop current control method in this paper greatly improves the steadystate performance, which not only restrains efficiently grid harmonic disturbance below $800 \mathrm{~Hz}$ but also tracks command signal below $2 \mathrm{kHz}$ well, and it has some practical merits in engineering application.

\section{Prototype Experiments}

The key parameters are $S_{N}=2.8 \mathrm{Mvar}, f_{c}=10.8 \mathrm{kHz}, f_{s}=216 \mathrm{kHz}, U_{N}=6 \mathrm{KV}$. The main processing chip used in the cascade STATCON is X3SD1800FG676 provided by Texas Instruments. The power switch device used is FF450R17ME4 provided by Infineon. The drive module is $2 \mathrm{SC} 0108 \mathrm{~T}$ provided by Concept. Operation effect is tested by oscilloscope.

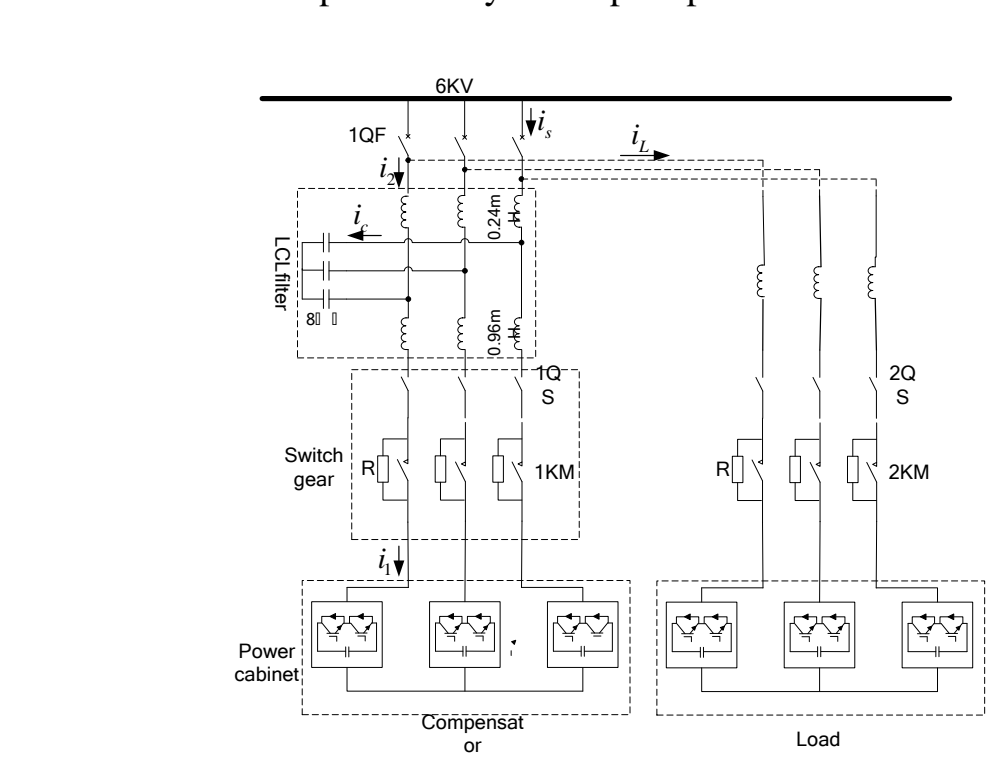

Figure 12. Diagram of prototype test

Consideration the limitation of the transformer capacity in the laboratory, two cascade STATCOM prototypes are accessing power grid, one simulates the load, and the other simulates the compensator, the structure is shown in Figure 12. 
This paper proves the validity of the control strategy in two aspects: steady state current compensation and dynamic response speed.

1. Steady state current compensation

(1) Close 1QF, before the compensator and the load are ready to run $\left(i_{\mathrm{s}}=\mathrm{i}_{2}=\mathrm{i}_{\mathrm{c}}=20 \mathrm{~A} ; \mathrm{i}_{1}=0 \mathrm{~A} ; \mathrm{i}_{\mathrm{L}}=0 \mathrm{~A}\right)$, the current is mainly the absorption capacitance current of the capacitors.

(2) Close 1QS, when the compensator puts into operation $\left(i_{s}=0 A ; i_{1}=i_{c}=20 A ; i_{L}=0 A\right)$, the compensator absorbs 20A inductive current and compensates the capacitive current completely.

(3) Close 2QS, the load puts into operation. As shown in Figure 13, channel 2, is B-phase current waveform of the compensator, channel 4 is B-phase current waveform of the load. The load acts as inductive load $\left(i_{\mathrm{L}}=142.61 \mathrm{~A} ; \mathrm{i}_{\mathrm{s}}=0 \mathrm{~A} ; \mathrm{i}_{1}=120.51 \mathrm{~A}\right)$, and the compensator absorbs $120.51 \mathrm{~A}$ capacitive current, with the addition of $20 \mathrm{~A}$ capacitive eturrent of the fixed capacitors, the compensator can be regarded having compensated the Inductive current completely with the tracking error of command signal of $1.47 \%$. Similary, the wave figure of compensating the harmonic current in Figure 14 shows that the compensator can compensate the inductive harmonic current completely with the tracking error of command signal of $3.12 \%$. Above all, the compensator has good steady frecision in compensating both undistorted current and harmonic current.

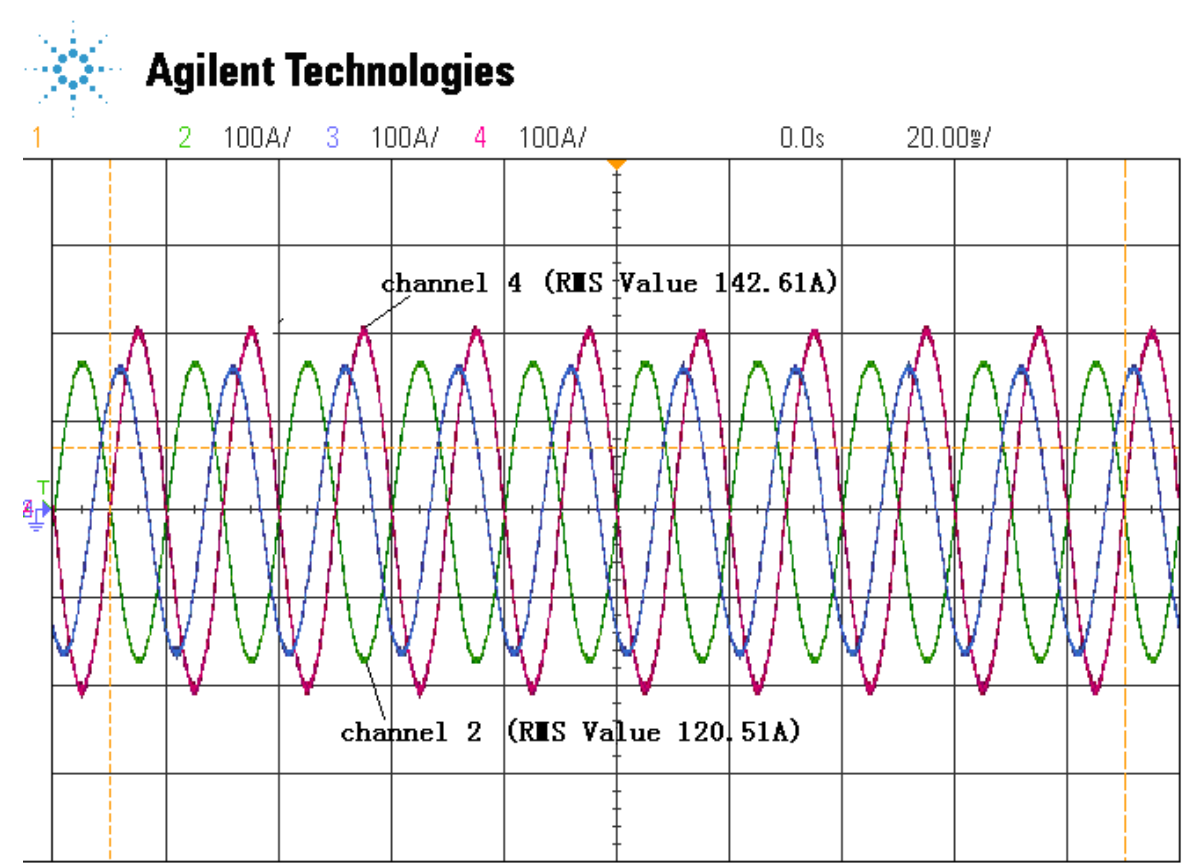

Figure 13. The static undistorted current compensation 


\section{Agilent Technologies}

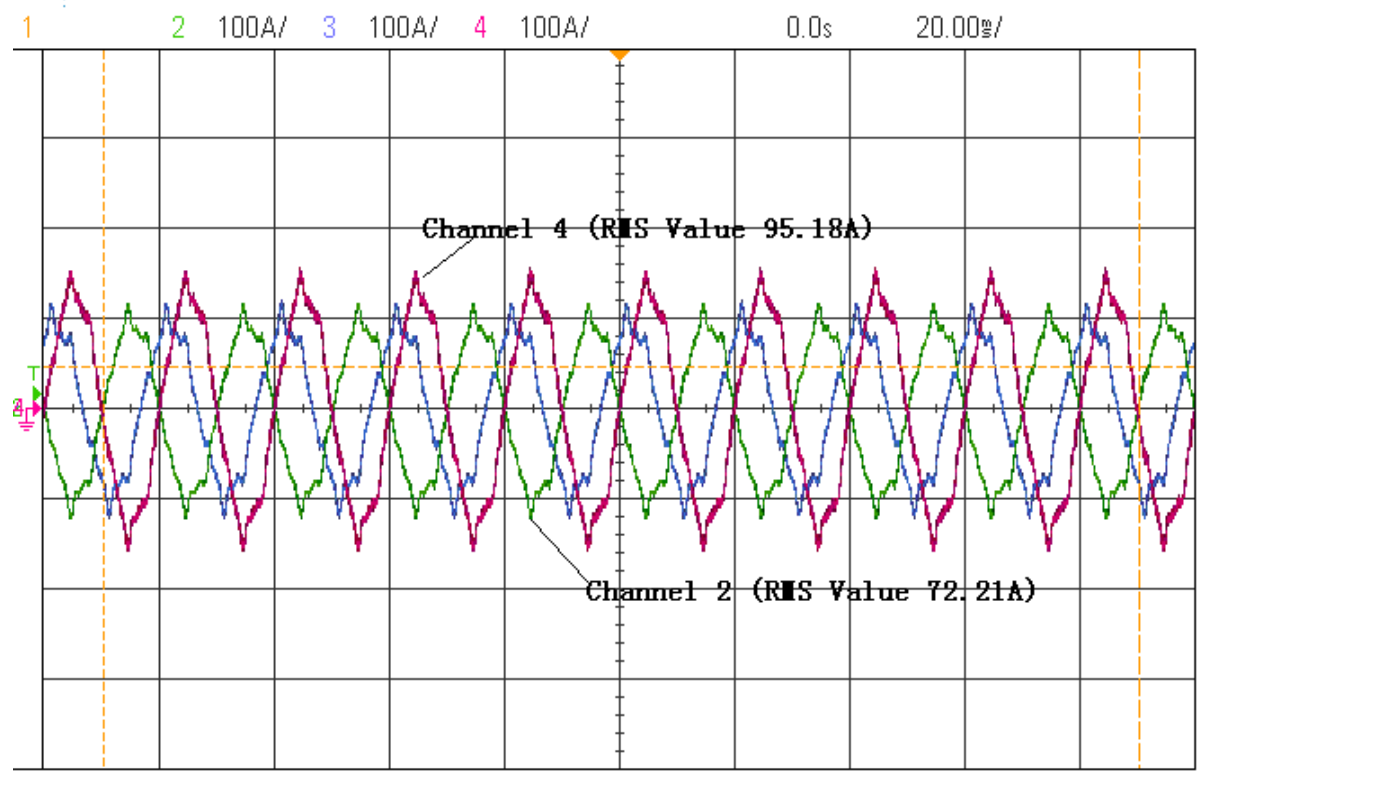

Figure 14. The static harmonic current compensation

2. Dynamic response speed

The dynamic response of the compensator in Figure 15 shows that the device has good dynamic performance and satisfies engineering demand.

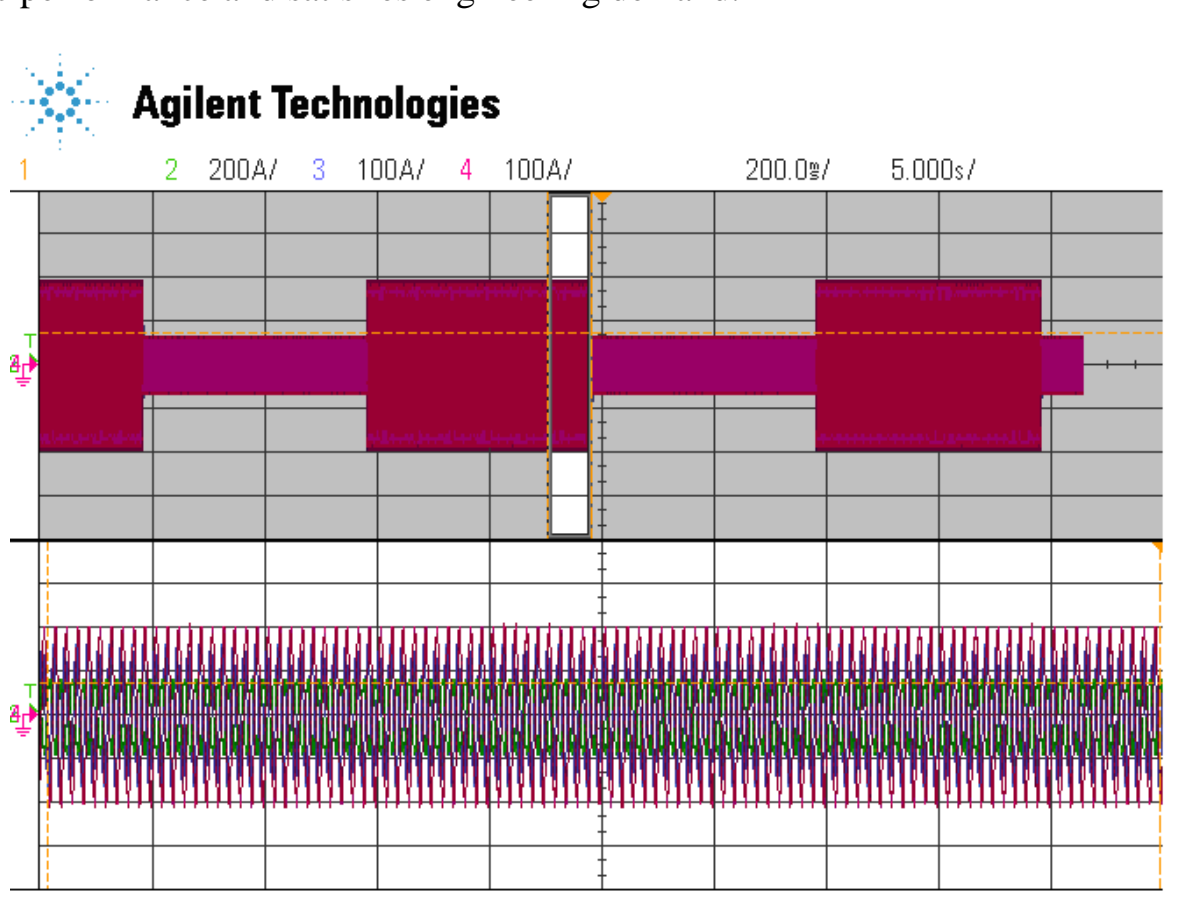

Figure 15. Dynamic current compensation 


\section{Conclusion}

This article puts forward the parameters design scheme of LCL filter with the consideration of the filtering effects of high-frequency ripple, voltage loss and the efficiency of the device. Then the problem of closed-loop stability of instantaneous grid-side current feedback control of LCL filter is solved by the time delay link and PI controller for ensuring high dynamic response and low-frequency stable precision. Finally, for the difficulty in eliminating static error of tracking harmonious command signals of the inner current control loop, the repetitive control loop based on internal principle is used as outer current to construct double-loop control, so that both high dynamic response and small steady-state error can be obtained. Simulation and the actual device experiments validate the feasibility of the design.

\section{Acknowledgements}

This work was supported by the Research Fund for the Doctoral Program of Higher Education of China under grant 20110095110014 and by the Key (Key grant) Project of Chinese Ministry of Education under grant 311021.

\section{References}

[1] K. Wanchai, A. Apinan and S. -N. Worawat, "Power factor mprovement and voltage harmonics reduction in pulse width modulation ac chopper using bee colony optimization", IETE Pechnical Review (Institution of Electronics and Telecommunication Engineers, India), vol. 30, Issue 3, (2013) May-June, pp.173-182.

[2] H. Park, J. Song and H. Wada M., "Comparative study on the position of shunt active power filters in $25 \mathrm{kV}$ AC railway systems", IETE Technical Reyiewanstitution of Efectronics and Telecommunication Engineers, India), vol. 29, Issue 5, (2012) September-October, pp. 421-431.

[3] R. Ahmed, "A position control review for photovoltajc system: Dual axis Sun Tracker", IETE Technical Review (Institution of Electronics and Telecommunfication Engineers, India), vol. 28, Issue 6, (2011) November-December, pp. 479-485.

[4] S. Mori, K. Matsuno and Te Hasgawa, "Development of large static var generator using self-commutated inverters for improving power system stability', IEEE Transactions on Power System, vol. 8, Issue 1, (1993), pp. 371-377.

[5] L. Wenhua, L. Xy and I. Qirong, "Development of 20Mvar STATCOM employing GTO inverters", Automation of Electric Power Systems, vol. 24, Issue 23, (2000), pp. 19-23.

[6] F. Z. Peng and J. S. Lai, "Dynami performance and control of a static var generator using cascade multilevel inverters", IEEE Transactions on Indurstry Applications, vol. 33, Issue 3, (1997), pp. 748-755.

[7] F. Z. Peng and J. S. Lai, "A (multilevel voltage-source inverter with separate DC sources for static var generation", IEEE Transacfions on Industry Applications, vol. 32, Issue 5, (1997), pp. 1130-1137.

[8] W. Zhaoan and L. Jinjun, "An advance of Harmonic Suppression and Reactive Power Compensation Technique for Power Electronic Equipment”, Power Electronics, vol. 31, Issue 1, (1997), pp. 100-104.

[9] F. Z. Peng, J. W. Mckeever and D. J. Adams, "A Multilevel Voltage-source Inverter with Separate DC Source for Static Var Generation”, IEEE Transactions on Industry Applications, vol. 32, Issue 5, (1996), pp. 11301138.

[10] C. Yao, Ximmin and T. Yibin, "Grid-side LCL filter of Three-Phase Voltage Source PWM Rectifier", Transactions of China Electrotechnical Society, vol. 2, Issue 9, (2007), pp. 124-129.

[11]C. Yunping, D. Kai and S. Jianjun, "Design of the LPF Employed in the link of the Shunt Active Power Filter and Power System", Automation of Electric Power System, Vol. 29, Issue 3, (2005), pp. 65-68.

[12] L. Fei, Z. Xiaoming and D. Shanxu, "Design and Research on Parameter of LCL Filter in Three-Phase GridConnected Inverter", Transactions of China Electrotechnical Society, vol. 25, Issue 3, (2010), pp. 111-112, 114.

[13]Z. Xianping, L. Yaxi and P. Lei, "Analysis and design of LCL type filter for three-phase voltage source rectifier”, Electro-technical Application, vol. 26, Issue 5, (2007), pp. 65-67.

[14] M. Salo and H. Tuusa, "A new control system with a control delay compensation for a current-source active power filter", IEEE Transactions on Industrial Electronics, vol. 52, (2005), pp. 1616-1624.

[15]E. Twining and D. G. Holmes, "Grid current regulation of a three-phase voltage source inverter with a LCL input filter”, IEEE Transactions on Power Electronics, vol. 18, Issue 3, (2003), pp. 888-895. 
[16] V. Blasko and V. Kaura, "A novel control to actively damp resonance in input LC filter of a three-phase voltage source converter", IEEE Transactions on Industrial Applications, vol. 33, Issue 2, (1997), pp. 542-550.

[17]X. Zhenglong, S. Liping, C. Libing and Y. Xiaodong, "Parameter design of cascade multilevel STATCOM in medium voltage based on LCL filter", Journal of China Coal Society, vol. 38, Issue 8, (2013), pp. 1503-1510.

[18] L. Fei, Z. Xiaoming and D. Shanxu, "Design and Research on Parameter of LCL Filter in Three-Phase GridConnected Inverter", Transactions of China Electrotechnical Society, vol. 25, Issue 3, (2010), pp. 111-112,114.

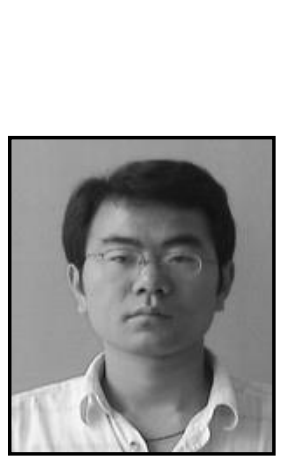

Zhenglong Xia. He is current a $\mathrm{PhD}$ candidate at China University of Mining and Technology (CUMT), China. He received his MS degree in Information and Electrical Engineering from CUMT in 2008, and his BS ${ }^{\bullet}$ degree in Information and Electrical Engineering from CUMT in 2005. $\mathrm{He}$ is currently a student at School of Information and Electrical Engineering, CUMT. His research interests are reactive compensation of

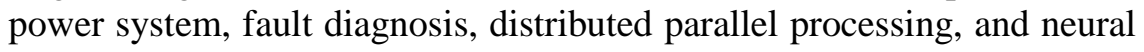
network.

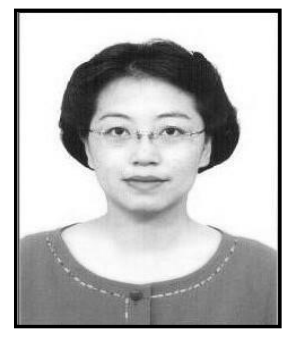

Liping Shi. She is born in 1964, Ph.D. She is a professor at School of Information and Electrical Engineering in CUMT. Her research interests are coal mine mechanical and electrical equipment and automation, application of power electronics in power systems, and equipment and power grid operation and fault diagnosis. She has published more than 30 research papers in jourhals and international conferences and she has won more than 10 the provinctal scientific research awards. Now she is presiding research fund for the Doctoral Program of Higher Education of China under grant 20110095/10014 and by the Key (Key grant) Project of Chinese Ministry of Education under grant 311021.

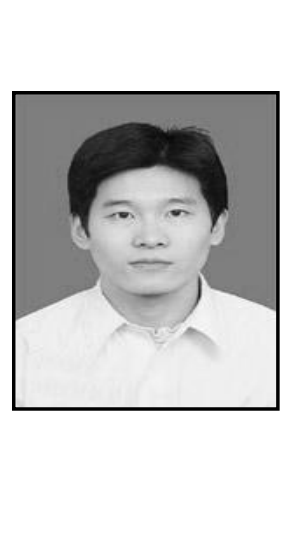

Xiaodong Yang. He is current a $\mathrm{PhD}$ candidate at China University of Mining and Technology (CUMT), China. He received his MS degree in Information and Electrical Engineering from CUMT in 2008 and his BS degree in Information and Electrical Engineering from CUMT in 2005. He is currently a student at School of Information and Electrical Engineering, CUMT. His research interests are fault diagnosis, distributed parallel processing, and neural network. 